\title{
Clinical Partial Response
}

National Cancer Institute

\section{Source}

National Cancer Institute. Clinical Partial Response. NCI Thesaurus. Code C123576.

A decrease in the size and the extent of tissue involvement by cancer, based on physical exam, such as palpation. 